\section{Salivary cortisol levels: the importance of clown doctors to reduce stress}

\author{
Flávia G. Saliba, 1 \\ Natanael S. Adiwardana, \\ Eliane U. Uehara, ${ }^{1}$ Renata N. Silvestre, ${ }^{1}$ \\ Victor V. Leite,1 Francisca T.V. Faleiros,1 \\ Flávia H.P. Padovani,2 \\ Juliana I.F. De Gobbi \\ 1Department of Pediatrics and \\ 2Department of Neurology, Psychology \\ and Psychiatry, Medical School of \\ Botucatu, São Paulo State University; \\ 3Department of Physiology, Institute of \\ Bioscience, São Paulo State University, \\ Botucatu, SP, Brazil
}

\section{Abstract}

This study was designed to correlate entertainment of clown-doctors (CD) activities on hospitalized children and aphysiological biomarker. For this purpose we collected saliva samples and verified children satisfaction with these activities by using a visual analog scale (VAS). Children from 6 to 7 years-old, with diagnosis of any acute pathology, interned in the Pediatric Ward of the Botucatu Medical School Hospital (São Paulo, Brazil) were interviewed. Two groups were taken into consideration: lunchCD and dinnerCD. The following protocol was applied in each group (lunch and dinner): collection of the first saliva sample and presentation of VAS prior to CD activities, followed by collection of a second saliva sample and another VAS assessment after CD activities. The salivary cortisol was reduced in both groups comparing the first saliva sample. The satisfaction of the intervention was evident for lunchCD. The CD intervention is effective in decreasing an important physiological biomarker of stress factor, cortisol, in hospitalized children, been effective for the healing process.

\section{Introduction}

The activities developed by clowns doctors (CD) are very well accepted and praised in hospital wards, especially in pediatric ones.1-3 Despite this recognition there is a lack of studies on the mechanisms involved in such activities. Factors such as hospitalization, distance from the family, hostile environment and apprehension caused by the unknown clinical procedure generates stress. ${ }^{4,5}$ One of the main hormones involved in stressful situations is corti- sol..$^{6-9}$ In order to validate the performance of CD and stimulates even more those activities, we measured salivary cortisol levels in children from the pediatric ward of a public hospital. We also evaluated the possible correlation between cortisol levels and satisfaction with these activities by using a visual analog scale (VAS).

\section{Materials and Methods}

\section{Participants}

Children aged 6 to 7 years from the Pediatric Ward of the Botucatu Medical School Hospital (Brazil) were recruited. Inclusion criteria were: a diagnosis of any acute pathology and a hospitalization period not exceeding 30 days. The parents or legal guardians agreed to the participation of their children in the study by signing the informed consent form. The procedures were approved by the Institutional Ethics Committee of the Botucatu Medical School (OF.116/2012-CEP). Thirty-six children accepted to participate in the whole study design.

The study was divided into two groups: lunchCD and dinnerCD. Each child in the study served as its own control. The following protocol was applied in each group (lunch and dinner): collection of the first saliva sample and presentation of the VAS prior to CD activities, followed by collection of a second saliva sample and another VAS assessment after CD activities. Forty-four children were excluded for one of the following reasons: use of corticosteroids, insufficient saliva sample in one of the collections, refusal to chew on the Salivette ${ }^{\circledR}$ (Sarstedt, Hermer, Germany) at the after time point, or presence of a chronic disease as stated in the medical records.

The CD perform activities in the library of the main ward and at bedside. The CD are composed of students that dedicate one hour (lunch and dinner) once a week to play with the kids. The visits take about one and a half hour and it was mainly about what the children would like most to do, some are involved with little stories, some with balloon designer; some sing songs and play instruments. Every visit is count on about 20 students that volunteer to play with the children, and depending on the day and the number of children at the ward, there are $2 \mathrm{CD}$ per children to play some activity. In case a child is under recovering from some small surgery the CD gives a balloon and leaves the room.

\section{Visual analog scale}

The age of 6 to 7 years, called preoperational development period, facilitates the use of a VAS to estimate satisfaction. We used a VAS of faces ranging from sadness to happiness in combination with a scale of descriptive adjec-
Correspondence: Juliana Irani Fratucci De Gobbi, Department of Physiology, Institute of Bioscience, São Paulo State University, UNESP, Distrito de Rubião Junior s/n, 18618-970, Botucatu, SP, Brazil.

Tel.: +55.14 .3880 .0319 - Fax: +55.14 .3815 .3744 .

E-mail: jdegobbi@ibb.unesp.br

Key words: Salivary cortisol; clowns doctors; biomarker of stress; visual analog scale.

Acknowledgments: we especially thank Prof $\mathrm{Dr}$ Carlos Roberto Padovani for expert and helpful statistical analyses. We also thank Hélio Kushima for technical assistance with cortisol analyses.

Contributions: the authors contributed equally.

Conflict of interest: the authors declare no potential conflict of interest.

Funding: this research was supported by São Paulo Research Foundation - FAPESP (\#12/14480-1) and Fundação para 0 Desenvolvimento da UNESP (FUNDUNESP) 229/2011.

Received for publication: 9 September 2015. Revision received: 22 January 2016.

Accepted for publication: 25 January 20016.

This work is licensed under a Creative Commons Attribution NonCommercial 4.0 License (CC BYNC 4.0).

(C) Copyright FG. Saliba et al., 2016

Licensee PAGEPress, Italy

Pediatric Reports 2016; 8:6188

doi:10.4081/pr.2016.6188

tives. The scale consisted of the following seven levels: 1 = very sad; 2 = sad; 3 = a little bit sad; 4 = unconcerned; 5 = slightly happy; 6 $=$ glad; $7=$ really happy. The scales were shown and read to the children, offering them an opportunity to give their opinion about the intervention.

\section{Saliva collection and analyses}

Saliva was collected with the Salivette $\AA$ (Sarstedt) device and processed according to manufacturer instructions. We provide the parents or legal guardians with some instructions, for instance, allowing the children without eating (including any kind of candy or gums) or drinking (except water) for 20 minutes previous the saliva collection, not brush or floss the teeth following the meals (only gargle with water), and ask children to brush the teeth only after the second saliva collection. In the lunch group, saliva was collected between 11:00-11:40 am before the intervention (before lunchCD) and between 1:45-2:15 pm after the 
Table 1. Age, internment reason and medication used for the participant children.

\begin{tabular}{|c|c|c|c|}
\hline Groups & Age (mean)* & Internment reason & Medication used \\
\hline CDlunch $(\mathrm{n}=18)$ & $6.5(6.02-7.05)$ & $\begin{array}{l}\text { Appendicitis }(\mathrm{n}=3) \text {; femur fracture }(\mathrm{n}=3) \text {; } \\
\text { adenoid hypertrophy }(\mathrm{n}=10) \text {; trachea trauma }(\mathrm{n}=2)\end{array}$ & $\begin{array}{c}\text { Cefazolin }(n=2) \text {, ceftriaxone }(n=2) \text {, ketoprofeno }(n=3) \text {, } \\
\text { dipyrone }(n=15) \text {, metronidazole }(n=4)\end{array}$ \\
\hline CDdinner $(\mathrm{n}=18)$ & $6.04(6-7.02)$ & $\begin{array}{c}\text { Appendicitis }(\mathrm{n}=3) \text {; bronchopneumonia }(\mathrm{n}=3) ; \\
\text { fimosis/parafimosis }(\mathrm{n}=4) \text {; adenoid hypertrophy }(\mathrm{n}=8)\end{array}$ & $\begin{array}{c}\text { Amoxicilin }(\mathrm{n}=6) ; \text { ceftriaxone }(\mathrm{n}=2) \text {, dipyrone }(\mathrm{n}=12) \text {; } \\
\text { tramadol }(\mathrm{n}=1)\end{array}$ \\
\hline
\end{tabular}

intervention (after lunchCD). The schedule for the dinner group was 5:15-5:40 pm (before dinnerCD) and 7:45-8:15 pm (after dinnerCD).

Salivary cortisol was analyzed by competitive enzyme immunoassay (ELISA, DiaMetra ${ }^{\circledR}$, Perugia, Italy) that provides the following limits of cortisol: $3-10 \mathrm{~g} / \mathrm{mL}$, for collections before lunch and g 0.6-2.5 g/mL for collections after lunch (according to specifications provided by the manufacturer, DiaMetra ${ }^{\circledR}$ ). This kit provides sensitivity in the determination of cortisol in a range of $0.5 \mathrm{~g} / \mathrm{mL}$ to $100 \mathrm{~g} / \mathrm{mL}$. The tests were conducted in triplicate for each sample. An intra-assay coefficient variation of $9.8 \%$ and an inter-assay coefficient variation of $15 \%$ were calculated according Jaedicke et al. ${ }^{10}$ The free diffusion of plasma cortisol to saliva ensures that salivary cortisol levels are as representative as the assessed directly in plasma. ${ }^{6-9}$

\section{Statistical analysis}

The results are expressed as median and percentiles $\left(25-75^{\text {th }}\right)$. Nonparametric repeated measures analysis of variance for independent samples was used to compare the same group, lunch or dinner, before and after the CD intervention. Spearman correlations between cortisol and VAS scores were analyzed.

\section{Results}

Table 1 shows the age, similar in the two groups, the internment reason and the medication in use by the interviewed children. The cortisol concentrations and VAS scores before and after lunchCD or dinnerCD are shown in Table 2. Salivary cortisol was reduced after the CD intervention in the lunch and dinner groups. Satisfaction with the CD intervention was significant in the lunchCD group, but not in the dinnerCD group. There was no association between cortisol and VAS scores after lunch $(0.065, \mathrm{P}>0.05)$, Figure 1A. However, Spearman's correlation test revealed an inverse association after dinner between cortisol and VAS $(-0.047, \mathrm{P}<0.05)$, Figure 1B.

Table 2. Salivary cortisol and visual analogy scale in inpatient children previous and after clown-doctors activities.

\begin{tabular}{lccc} 
Variables, groups & Previous & After & P value \\
Salivary cortisol & & & \\
lunchCD & $2.88(1.06 ; 11.25)$ & $2.16(0.97 ; 3.25)$ & $<0.01$ \\
dinnerCD & $1.75(1.00 ; 7.91)$ & $1.32(0.40 ; 2.42)$ & $<0.01$ \\
VAS & & & \\
lunchCD & $6(1: 7)$ & $7(5: 7)$ & $<0.01$ \\
dinnerCD & $6(3 ; 7)$ & $6(1: 7)$ & $>0.05$ \\
\hline
\end{tabular}

Results are expressed as median and $25^{\text {th }}-75^{\text {th }}$ percentiles. VAS, visual analogy scale; $\mathrm{CD}$, clown-doctors. Cortisol levels were measured as $\eta g / \mathrm{mL}$. $\mathrm{N}=18$, either lunchCD or dinnerCD. In the lunchCD group there were 8 males and 10 females, and in the dinnerCD group there were 11 males and 8 females.
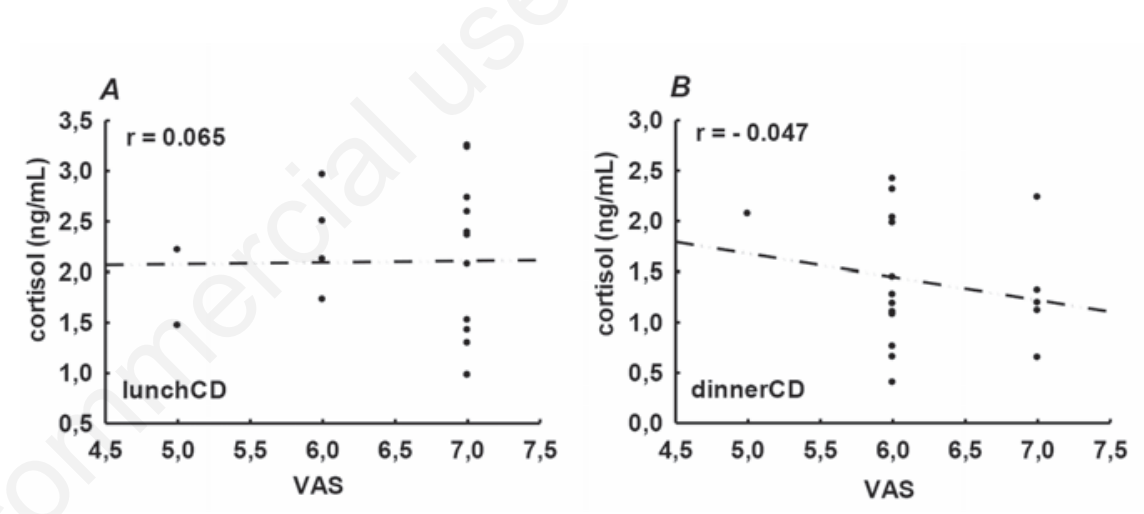

Figure 1. Spearman correlation between salivary cortisol and Visual Analogue Scale (VAS) after (A) lunchCD and after (B) dinnerCD; $n=18$ in each group. The $r$ values for the linear correlation are in the top of the figure.

\section{Discussion}

The present results validate $\mathrm{CD}$ activities to be effective in decreasing cortisol levels, a biomarker of stress, in the studied groups. Satisfaction with the CD intervention rated on VAS was evident in the lunchCD group, but not in the dinnerCD group. However, there was a negative correlation between cortisol levels and VAS scores in the dinnerCD group; the lower the cortisol levels, the higher the VAS score. The well-being associated with CD activities, seen by the VAS, might be related to a reduction in cortisol levels. Cortisol secretion is higher in the morning than throughout the day. ${ }^{11}$ The significant decrease in cortisol lev- els in the lunchCD group occurred within only 2 hours what may reflect a true effect of $\mathrm{CD}$ activities and not only a random effect of circadian variation. Furthermore, in the dinnerCD group the intervention decreased cortisol levels, even when its levels were already low. Although, there is a popular believes that CD is amusement for the patients and reduces stress even for parents and hospital staff, ${ }^{1-3}$ this study proved that $\mathrm{CD}$ is beneficial for reducing cortisol. Thus, decreased levels of cortisol attenuate the effects of hospitalization stress, contributing to the healing process.

In agreement with the present results a decrease in salivary cortisol levels has also been observed in hospitalized children after playful activities, ${ }^{12}$ reinforcing that $\mathrm{CD}$ activi- 
ties are effective in reducing stress. Our results support CD activities as an important and valid tool to reduce a recognized physiological biomarker of stress. We emphasize that VAS did not change for the after dinnerCD time point since during the afternoon the children had the opportunity to play in a variety of activities provided by volunteers of different non-profit organizations or even religious organizations. Those volunteers read stories, play instruments and sing songs together with children and parents helping to minimize the sorrows of being waiting for diagnoses and the healing process. These interventions may also help reduce cortisol levels. When they were asked about their satisfaction with one more activity, the last in the day the dinnerCD in the ward, they seemed not to be as satisfied as after lunchCD. Furthermore, at night the children were supposed to go back home to sleep with their family and their belongings, a fact that might explain why the children interviewed at night were not as satisfied as the children interviewed in the afternoon. Usually during the morning there are cleaning and nurse staff taking care of details and there is not much time for playing than it is in the afternoon. Children in the present study were mostly happy by the VAS, what might suggest that they were not in a psychophysiological reaction of the stress as named by Seyle in his studies. ${ }^{13}$ Though in the present study the psychological assessment of the children was not our focus and deserves further investigations.

\section{Conclusions}

The present results provided physiological evidence of the beneficial effects of playful CD activities in a public pediatric ward. Therefore the $\mathrm{CD}$ activities should be more valuated and encourage inside a hospital atmosphere, once it reduces an important physiological stress factor in hospitalized children.

\section{References}

1. Bennett MP, Lengacher CA. Humor and laughter may influence health: III. Laughter and health outcomes. Evid Based Complement Alternat Med 2008;5:37-40.

2. Vagnoli L, Caprilli S, Robiglio A, Messeri A. Clown doctors as a treatment for preoperative anxiety in children: a randomized, prospective study, Pediatrics 2005;116: e563-7.

3. Barkmann C, Siem AK, Wessolowski N, Schulte-Markwort M. Clowning as a supportive measure in paediatrics - a survey of clowns, parents and nursing staff. BMC Pediatr 2013;13:166.

4. Dionigi A, Sangiorgi D, Flangini R. Clown intervention to reduce preoperative anxiety in children and parents: a randomized controlled trial. J Health Psychol 2014;19: 369-80.

5. Fry WF. The physiologic effects of humor, mirth, and laughter. JAMA 1992;267:1857-8.
6. Kirschbaum C, Hellhammer DH. Salivary cortisol in psychoneuroendocrine research: recent developments and applications. Psychoneuroendocrinology 1994;19:313-33.

7. Hellhammer DH, Wüst $S$, Kudielka BM. Salivary cortisol as a biomarker in stress research. Psychoneuroendocrinology 2009;34:163-71.

8. Umeda T, Hiramatsu R, Iwaoka T, et al. Use of saliva for monitoring unbound free cortisol levels in serum. Clin Chim Acta 1981;110: 245-53.

9. Kudielka BM, Buske-Kirschbaum A, Hellhammer DH, Kirschbaum C. HPA axis responses to laboratory psychosocial stress in healthy elderly adults, younger adults, and children: impact of age and gender. Psychoneuroendocrinology 2004;29:83-98.

10. Jaedicke KM, Taylor JJ, Preshaw PM. Validation and quality control of ELISAs for the use with human saliva samples. J Immunol Methods 2012;377:62-5.

11. Chung S, Son GH, Kim K. Circadian rhythm of adrenal glucocorticoid: its regulation and clinical implications. Biochim Biophys Acta 2007;1812:581-91.

12. Yount G, Rachlin K, Siegel J. Expressive arts therapy for hospitalized children: a pilot study measuring cortisol levels. Pediatr Rep 2013;5:e7.

13. Seyle H. Forty years of stress research: principal remaining problems and misconceptions. Can Med Assoc J 1976;115:53-6. 